SCTM 215-59(51)

\title{
TABULATION OF THE HYPERGEOME TRIC PROBABILITY DISTRIBUTION FOR LOT SIZES LESS THAN OR EQUAL TO 50
}

D. B. Owen, 5125

\begin{abstract}
This memorandum describes a tabulation (too large to be included in the memorandum) of the hypergeometric probability distribution for lot sizes up to and including 50. Uses of the tabulation in sampling inspection and reliability are described. The tabulation provides a simple way of testing the equality of two proportions when the total number of observations on the proportions does not exceed 50 .
\end{abstract}

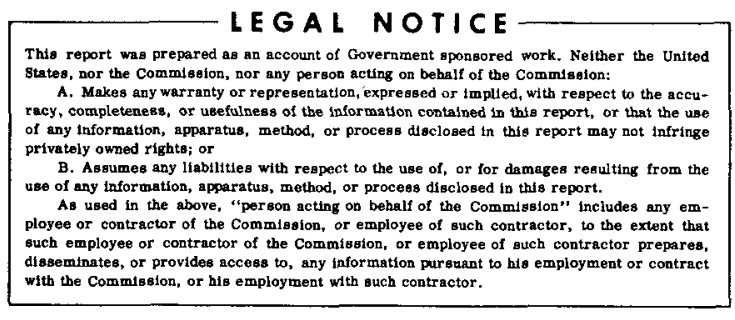

Case No. 417.00

Augu st 13, 1959

$$
\therefore i \quad 201
$$




\section{DISCLAIMER}

This report was prepared as an account of work sponsored by an agency of the United States Government. Neither the United States Government nor any agency Thereof, nor any of their employees, makes any warranty, express or implied, or assumes any legal liability or responsibility for the accuracy, completeness, or usefulness of any information, apparatus, product, or process disclosed, or represents that its use would not infringe privately owned rights. Reference herein to any specific commercial product, process, or service by trade name, trademark, manufacturer, or otherwise does not necessarily constitute or imply its endorsement, recommendation, or favoring by the United States Government or any agency thereof. The views and opinions of authors expressed herein do not necessarily state or reflect those of the United States Government or any agency thereof. 


\section{DISCLAIMER}

Portions of this document may be illegible in electronic image products. Images are produced from the best available original document. 
Blank Page 


\section{TABLE OF CONTENTS}

\section{Page}

Introduction

Applications to Sampling Inspection Plans

Applications to Tests of the Equality of Two Proportions (Two-by-Two Tables)

Applications to the Distribution of the Number of Exceedances

Applications to a Sequential Procedure

Number of Entries in the Table

APPENDIX 


\section{TABULATION OF THE HYPERGEOMETRIC PROBABILITY DISTRIBUTION FOR LOT SIZES LESS THAN OR EQUAL TO 50}

\section{Introduction}

A tabulation of the hypergeometric probability distribution has been made at Sandia Corporation. This tabulation has many applications, some of which are described below. Since the nomenclature of sampling inspection was used to set up the tabulation described in this memorandum, this nomenclature will be used here. The following symbols are defined:

$N=$ Number of items in a lot,

$N^{*}=$ Number of items in a sample taken from the lot,

$\mathrm{K}^{*}=$ Number of defective items in the lot, and

$\mathrm{X}=$ Number of defective items observed in the sample.

Then

$\operatorname{Pr}\{$ Exactly $X$ defectives in the sample $\}=P X *$

$$
=\frac{K^{*} ! N^{*} !}{\left(K^{*}-X\right) !\left(N^{*}-X\right) ! X !} \quad \frac{\left(N-K^{*}\right) !\left(N-N^{*}\right) !}{N !\left(N-K^{*}-N^{*}+X\right) !},
$$

where $X$ is an integer such that $\max \left[0, N^{*}+K^{*}-N\right] \leq X \leq \min \left[N^{*}, K^{*}\right]$, and

$\operatorname{Pr}\{\mathrm{X}$ defectives or less in the sample $\}=P X$

$$
=\sum_{i=\max \left[0, N^{*}+K^{*}-N\right]}^{X} \frac{K^{*} ! N^{*} !}{\left(K^{*}-i\right) !\left(N^{*}-i\right) ! i !} \frac{\left(N-K^{*}\right) !\left(N-N^{*}\right) !}{N !\left(N-K^{*}-N^{*}+i\right) !} .
$$

Since $N^{*}$ and $\mathrm{K}^{*}$ may be interchanged in either of the probabilities PX and $P X *$ without changing the value of the probabilities, it is necessary to tabulate only for $\mathrm{K}^{*} \leq \mathrm{N}^{*}$. If $\mathrm{N}^{*}<\mathrm{K}^{*}$, it is necessary to enter the table with $\mathrm{N}^{*}$ and $\mathrm{K}^{*}$ inter changed, and the probabilities may be read directly from the table. 
The table that has been made tabulates exhaustively all hypergeometric probabilities for $N \leq 50$, with the restriction that $K^{*} \leq N^{*}$. In view of the preceding paragraph, this, of course, is no restriction at all, and it is possible to say that all hypergeometric probabilities for $\mathrm{N} \leq 50$ have been tabulated.

Because of the large size of the table only a few copies were made. Copies were available in Organizations 1592-1 (B. Ostle), 5511-3 (J. C. Connell), and 5125 (D. B. Owen) when this memorandum was written. The appendix, page 23, is a copy of the first 10 pages of the hypergeometric table. The entire table contains 3231 pages.

Three additional symmetries in the hypergeometric distribution were not used when the table was prepared. These are:

If

$$
P^{*}\left(N, N^{*}, K^{*}, X\right)=P X^{*}=\frac{K^{*} ! N^{*} !}{\left(K^{*}-X\right) !\left(N^{*}-X\right) ! X !} \frac{\left(N-K^{*}\right) !\left(N-N^{*}\right) !}{N !\left(N-K^{*}-N^{*}+X\right) !},
$$

then

$$
\begin{aligned}
P *\left(N, N^{*}, K^{*}, X\right) & =P *\left(N, N *, N-K^{*}, N^{*}-X\right) \\
& =P *\left(N, N-N^{*}, K^{*}, K^{*}-X\right) \\
& =P *\left(N, N-N^{*}, N-K^{*}, N-N^{*}-K^{*}+X\right) .
\end{aligned}
$$

Similarly, if

$$
\begin{aligned}
& P\left\{N, N^{*}, K^{*}, X\right\}=P X \\
& =\sum_{i=\max \left[0, N^{*}+K^{*}-N^{\prime}\right]}^{X} \frac{K^{*} ! N^{*} !}{\left(K^{*}-i\right) !\left(N^{*}-i\right) ! i !} \frac{\left(N-K^{*}\right) !\left(N-N^{*}\right) !}{N !\left(N-K^{*}-N^{*}+i\right) !},
\end{aligned}
$$

then

$$
\begin{aligned}
\mathrm{P}\left\{\mathrm{N}, \mathrm{N}^{*}, \mathrm{~K}^{*}, \mathrm{X}\right\} & =\mathrm{P}\left\{\mathrm{N}, \mathrm{N}-\mathrm{N}^{*}, \mathrm{~N}-\mathrm{K}^{*}, \mathrm{~N}-\mathrm{N}^{*}-\mathrm{K}^{*}+\mathrm{X}\right\} \\
& =1-\mathrm{P}\left\{\mathrm{N}, \mathrm{N}^{*}, \mathrm{~N}-\mathrm{K}^{*}, \mathrm{~N}^{*}-\mathrm{X}-1\right\} \\
& =1-\mathrm{P}\left\{\mathrm{N}, \mathrm{N}-\mathrm{N}^{*}, \mathrm{~K}^{*}, \mathrm{~K}^{*}-\mathrm{X}-1\right\}
\end{aligned}
$$

The symmetry mentioned above involving the interchangeability of $\mathrm{N}^{*}$ and $\mathrm{K}^{*}$ may be written

$$
\mathrm{P} *\{\mathrm{~N}, \mathrm{~N} * \mathrm{~K} * \mathrm{X}\}=\mathrm{P} *\left\{\mathrm{~N}, \mathrm{~K} *, \mathrm{~N}^{*}, \mathrm{X}\right\},
$$

and

$$
P\left\{N, N^{*}, K^{*}, X\right\}=P\left\{N, K^{*}, N^{*}, X\right\} .
$$


The preceding symmetries mean that most (but not all) of the entries in the table appear four times. For example, the following entries are noted:

\begin{tabular}{llrrrr}
$N$ & N* & K* & \multicolumn{1}{l}{ X } & PX & PX* \\
50 & 20 & 10 & 0 & 0.00292486 & 0.00292486 \\
50 & 40 & 20 & 20 & 1.00000039 & 0.00292486 \\
50 & 30 & 10 & 10 & 1.00000057 & 0.00292486 \\
50 & 40 & 30 & 20 & 0.00292486 & 0.00292486
\end{tabular}

For these entries, PX* is the same. Because of the method of computation, however, these values would not have to be exactly the same, and in some instances equivalent entries may differ as much as five in the seventh decimal place.

The error in any entry in the table for PX and PX* is not more than two in the sixth decimal place. This is more than accurate enough for most applications.

As a further example of the duplication of entries, consider the following four sets of equivalent entries:

Set I

\begin{tabular}{ccrrrr}
$N$ & $\underline{N}$ & K* & X & $\mathrm{PX}$ & $\mathrm{PX} *$ \\
\hline 16 & 10 & 4 & 0 & 0.00824176 & 0.00824176 \\
16 & 10 & 4 & 1 & 0.11813180 & 0.10989004 \\
16 & 10 & 4 & 2 & 0.48901094 & 0.37087914 \\
16 & 10 & 4 & 3 & 0.88461533 & 0.39560439 \\
16 & 10 & 4 & 4 & 0.99999996 & 0.11538463
\end{tabular}

Set II

\begin{tabular}{crrrrr}
$\frac{N}{N}$ & $N^{*}$ & $\mathrm{~K}^{*}$ & \multicolumn{1}{l}{$\mathrm{X}$} & $\mathrm{PX}$ & $\mathrm{PX}$ \\
16 & 6 & 4 & 0 & 0.11538459 & 0.11538459 \\
16 & 6 & 4 & 1 & 0.51098891 & 0.39560431 \\
16 & 6 & 4 & 2 & 0.88186796 & 0.37087908 \\
16 & 6 & 4 & 3 & 0.99175803 & 0.10989004 \\
16 & 6 & 4 & 4 & 0.99999978 & 0.00824175
\end{tabular}

Set III

$\begin{array}{ccrrrr}\text { N } & \text { N* } & \text { K* } & \text { X } & \text { PX } & \text { PX* } \\ 16 & 12 & 6 & 2 & 0.00824176 & 0.00824176 \\ 16 & 12 & 6 & 3 & 0.11813180 & 0.10989004 \\ 16 & 12 & 6 & 4 & 0.48901094 & 0.37087914 \\ 16 & 12 & 6 & 5 & 0.88461533 & 0.39560439 \\ 16 & 12 & 6 & 6 & 0.99999996 & 0.11538463\end{array}$


Set IV

\begin{tabular}{|c|c|c|c|c|c|}
\hline $\mathbf{N}$ & $\mathrm{N} *$ & $\mathrm{~K}^{*}$ & $\mathrm{X}$ & PX & PX* \\
\hline 16 & 12 & 10 & 6 & 0.11538463 & 0.11538463 \\
\hline 16 & 12 & 10 & 7 & 0.51098902 & 0.39560439 \\
\hline 16 & 12 & 10 & 8 & 0.88186815 & 0.37087914 \\
\hline 16 & 12 & 10 & 9 & 0.99175820 & 0.10989004 \\
\hline 16 & 12 & 10 & 10 & 0.99999996 & 0.00824176 \\
\hline
\end{tabular}

Clearly, when one of the sets of values is given, it would be easy to obtain the other three. Also, since the entries differ in the last places, it is clear that independent and not entirely equivalent calculations were made.

\section{Applications to Sampling Inspection Plans}

For a lot of size $\mathbf{N}=12$, a sample $N^{*}=5$ is taken and the lot is accepted if $X=0$ defectives are found in the sample. The probability of acceptance for various proportions defective in the lot is needed. From the table one can read:

\begin{tabular}{|c|c|c|c|c|}
\hline $\mathrm{N}$ & $\underline{N *}$ & $\underline{K^{*}}$ & $\underline{X}$ & PX \\
\hline 12 & 5 & 0 & 0 & 1.0000 \\
\hline 12 & 5 & 1 & 0 & 0.5833 \\
\hline 12 & 5 & 2 & 0 & 0.3182 \\
\hline 12 & 5 & 3 & 0 & 0.1591 \\
\hline 12 & 5 & 4 & 0 & 0.0707 \\
\hline 12 & 5 & 5 & 0 & 0.0265 \\
\hline 12 & 5 & 6 & 0 & 0.0076 \\
\hline 12 & 5 & 7 & 0 & 0.0013 \\
\hline
\end{tabular}

If $\mathrm{K}^{*}$ gets above $7=\mathrm{N}-\mathrm{N} *+\mathrm{X}$, the probability of acceptance is zero, since then it is impossible to get five nondefective items in the sample. Also, if $\mathrm{K}^{*}=0$, the probability of acceptance is one, since then the lot is surely accepted. Hence the operating characteristic for this plan is obtained by plotting PX against $\mathrm{K} * / \mathrm{N}$. The result is shown in Figure 1. 


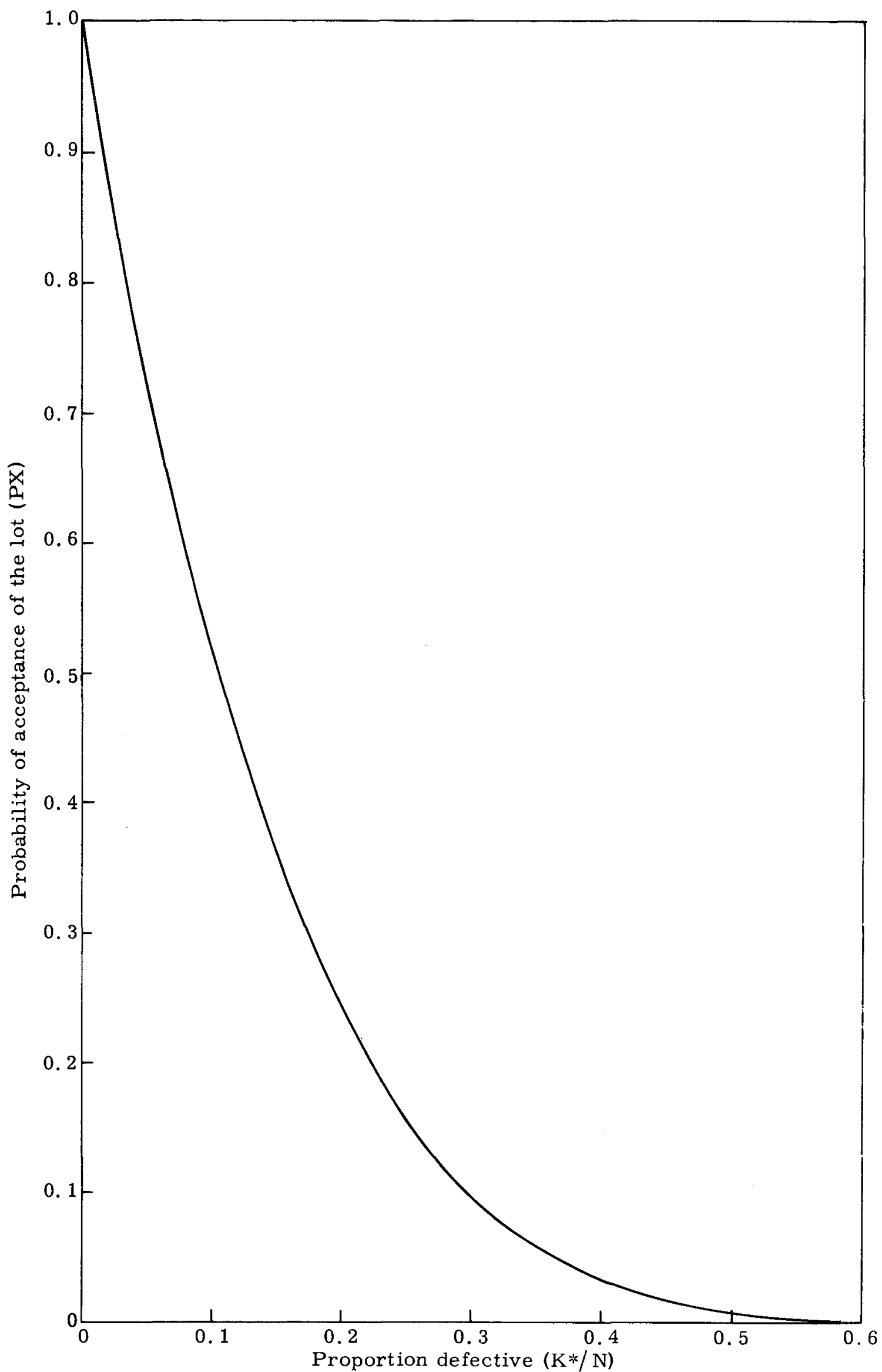

Figure 1. Operating-Characteristic Curve for $N=12, N *=5$, and $X=0$

$\therefore 80$

9 
As a second example, consider a lot of size $N=25$, where a sample of size $N^{*}=10$ is taken and the lot is accepted if $X=0$ or 1 defectives are found in the sample. The following entries are found in the table.

\begin{tabular}{rrrrr} 
N & N* & K* & X & PX \\
\hline 25 & 10 & 0 & 1 & 1.0000 \\
25 & 10 & 1 & 1 & 1.0000 \\
25 & 10 & 2 & 1 & 0.8500 \\
25 & 10 & 3 & 1 & 0.6543 \\
25 & 10 & 4 & 1 & 0.4676 \\
25 & 10 & 5 & 1 & 0.3134 \\
25 & 10 & 6 & 1 & 0.1978 \\
25 & 10 & 7 & 1 & 0.1175 \\
25 & 10 & 8 & 1 & 0.0654 \\
25 & 10 & 9 & 1 & 0.0339 \\
25 & 10 & 10 & 1 & 0.0162 \\
25 & 10 & 11 & 1 & 0.0070 \\
25 & 10 & 12 & 1 & 0.0027 \\
25 & 10 & 13 & 1 & 0.0009 \\
25 & 10 & 14 & 1 & 0.0002 \\
25 & 10 & 15 & 1 & 0.0000 \\
25 & 10 & 16 & 1 & 0.0000
\end{tabular}

If $\mathrm{K}^{*}>\mathrm{N}-\mathrm{N} *+\mathrm{X}$, then $\mathrm{PX}$ is zero; and if $\mathrm{K}^{*} \leq \mathrm{X}$, then $\mathrm{PX}$ is one. Hence the values above $K^{*}=16$ have been omitted, and the values for $K *=0$ and 1 have been added for convenience in plotting. Figure 2 shows the graph of the operatingcharacteristic curve of this example.

\section{Applications to Tests of the Equality of Two Proportions (Two-by-Two Tables)}

A two-by-two contingency table may be represented as follows:

Characteristic I

\begin{tabular}{|c|c|c|c|}
\hline Characteristic II & Has & Does not have & Totals \\
\hline Has & $\mathrm{x}$ & $\mathrm{K} *-\mathrm{X}$ & $\mathrm{K}$ * \\
\hline Does not have & $N *-X$ & $N-N *-K^{*}+X$ & $N-K \%$ \\
\hline Totals & $\mathrm{N} *$ & $N-N *$ & $\mathrm{~N}$ \\
\hline
\end{tabular}




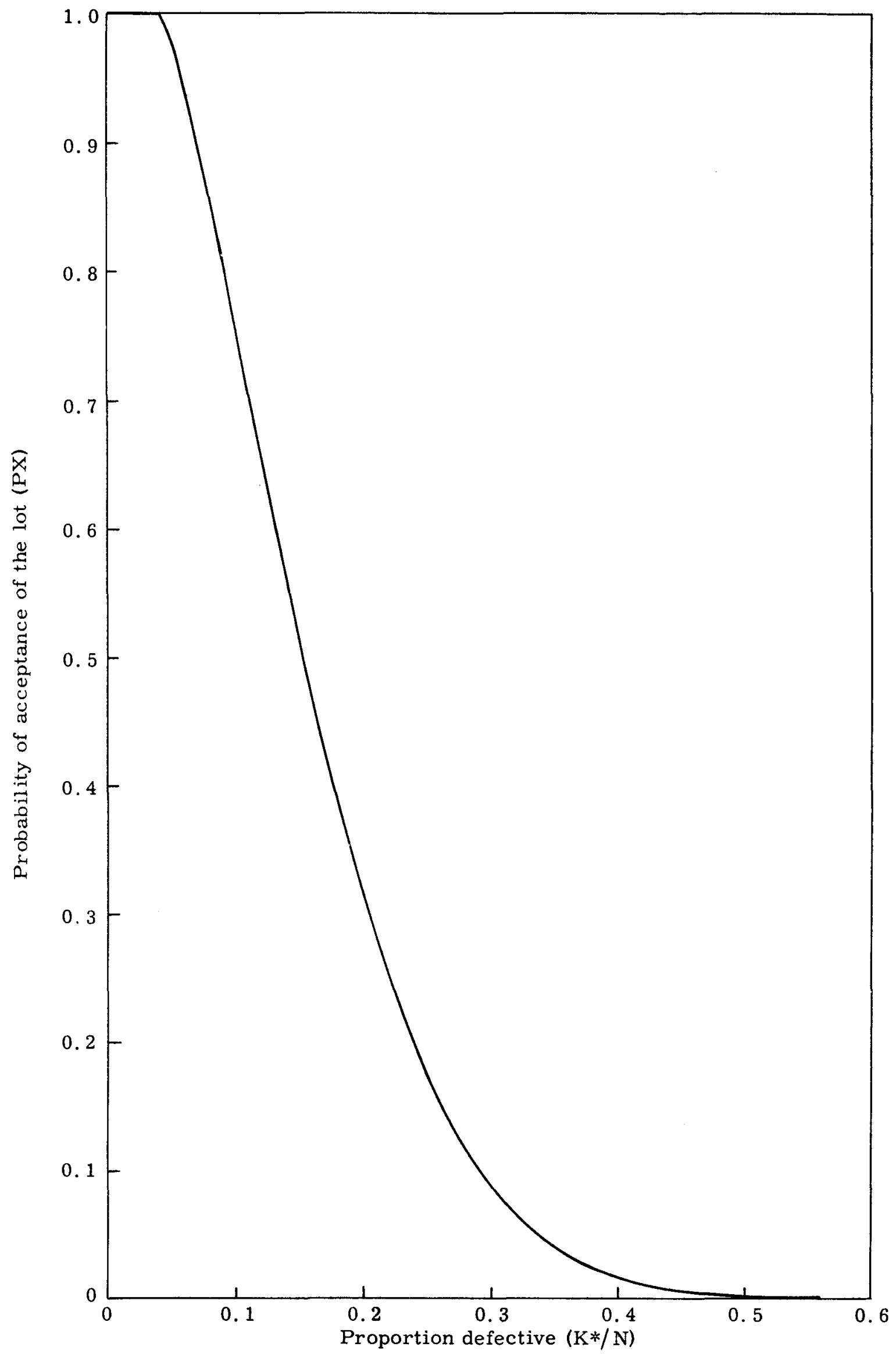

Figure 2. Operating-Characteristic Curve for $N=25, N^{*}=10$, and $X=0$ or 1 
An example will make clear the usefulness of the hypergeometric table in testing a two-by-two table. The problem given on page 19 of Reference 1 will be solved again here. The problem is presented as follows:

$$
\text { Performance of Encapsulated SA-1's }
$$

\begin{tabular}{lcccc}
\multicolumn{1}{c}{ Treatment } & Failure & & Success & Totals \\
\cline { 1 - 1 } Encapsulation Method I & 9 & & 6 & 15 \\
Encapsulation Method II & 3 & & 11 & 14 \\
Totals & 12 & & 17 & 29
\end{tabular}

Hence, take $N^{*}=12, \mathrm{~K}^{*}=15, \mathrm{X}=9$, and $\mathrm{N}=29$. But to read this from the hypergeometric table, it is necessary to interchange $K^{*}$ and $N^{*}$. Page 382 of the table contains the following entries:

$\begin{array}{lrrrrr}N & \text { N* } & \text { K* } & \text { X } & \text { PX } & \text { PX* } \\ 29 & 15 & 12 & 0 & 0.00000175 & 0.00000175 \\ 29 & 15 & 12 & 1 & 0.00010696 & 0.00010521 \\ 29 & 15 & 12 & 2 & 0.00213226 & 0.00202530 \\ 29 & 15 & 12 & 3 & 0.01968488 & 0.01755261 \\ 29 & 15 & 12 & 4 & 0.09867170 & 0.07898681 \\ 29 & 15 & 12 & 5 & 0.29726710 & 0.19859540 \\ 29 & 15 & 12 & 6 & 0.58688549 & 0.28961839 \\ 29 & 15 & 12 & 7 & 0.83512970 & 0.24824421 \\ 29 & 15 & 12 & 8 & 0.95925176 & 0.12412206 \\ 29 & 15 & 12 & 9 & 0.99435702 & 0.03510526 \\ 29 & 15 & 12 & 10 & 0.99962280 & 0.00526578 \\ 29 & 15 & 12 & 11 & 0.99999103 & 0.00036823 \\ 29 & 15 & 12 & 12 & 0.99999979 & 0.00000876\end{array}$

According to Reference 1 (page 19):

"The question to be answered is: Does encapsulation Method II have a better effect on performance than encapsulation Method I ? This is a one-sided test since the outcome is interesting only if Method II is better than Method I. ... the relative proportion of successes using Method II is $11 / 14=0.79$ and for Method I is $6 / 15=0.40$. Hence, in this sample, Method II shows a better performance than Method I. The question now is: Is this due to chance or is Method II really better than Method I? Next, the statistical test will be performed. If Method II were worse than Method I in the sample, then no further statistical test would be performed because the hypothesis that Method II is no better than Method I is automatically accepted.

"(Note: The procedure outlined above enables one to make a one-tailed test. For a two-tailed test no preliminary look at the proportions is necessary.)" 
The probability of observing exactly nine failures is then $P X *=0.03510526$. But it is necessary to find the probability of nine or more failures (a deviation as extreme as, or more extreme than, that observed), and this can be obtained from the table by taking

$$
1-\operatorname{Pr}\{\mathrm{X} \leq 8\}=1-0.95925176=0.04074824 \text {. }
$$

Since this probability is less than 0.05 , there is a significant difference between Encapsulation Method I and Encapsulation Method II at the 95-percent level of significance.

If in the problem solved above there were no prior understanding that the outcome be interesting only if Method II were better than Method I, than a twosided test should be run, and looking at the table quoted above one should say there is a significant difference at the 95 -percent level of significance only if $\mathrm{X} \leq 3$ or if $X \geq 10$, since

$$
\begin{aligned}
\operatorname{Pr}\{\mathrm{X} \leq 3\}+\operatorname{Pr}\{\mathrm{X} \geq 10\} & =0.01968488+1-0.99435702 \\
& =0.02532786<0.05 .
\end{aligned}
$$

The tabulation on page 12 shows that $X$ cannot be raised to 4 , since then $P X=0.09867170$. But $X$ could be lowered to 9 at the upper end if $X$ were lowered to 2 at the lower end. That is, another two-sided rule for calling significance at the 95 -percent significance level is if $X \leq 2$ or if $X \geq 9$, since

$$
\begin{aligned}
\operatorname{Pr}\{X \leq 2\}+\operatorname{Pr}\{X \geq 9\} & =0.00213226+1-0.95925176 \\
& =0.04288050<0.05 .
\end{aligned}
$$

Both rules, $X \leq 3$ or $X \geq 10$, and $X \leq 2$ or $X \geq 9$, are equally good. The second might be preferred over the first since the actual test probability is closer to 0.05. The first might be preferred to the second since both tails of the distribution are below 0.025 . The difficulty, of course, arises because of the discreteness of X. For further discussion of this point see Reference 1.

Applications to the Distribution of the Number of Exceedances

Consider a random sample of size $n$ taken from a continuous distribution. Let another random sample, of size $m$ independent of the first sample, be drawn 
from the same population. The probability that $X$ observations among the observations of the second sample will exceed the $r^{\text {th }}$ largest observation in the first sample is given by

$\operatorname{Pr}\left\{\mathrm{X}\right.$ among $\mathrm{m}$ future trials will exceed the $\mathrm{r}^{\text {th }}$ largest observation in a sample of $\left.\mathrm{n}\right\}$

$$
\begin{aligned}
& =\left(\begin{array}{c}
m+n-r-X \\
n-r
\end{array}\right)\left(\begin{array}{c}
x+r-1 \\
r-1
\end{array}\right) /\left(\begin{array}{c}
m+n \\
n
\end{array}\right) \\
& =\frac{n}{m+n} P *(m+n-1, m, X+r-1, X) \\
& =\frac{r}{X+r} P *(m+n, m, X+r, X),
\end{aligned}
$$

where the $\mathrm{P} *()$ is the quantity defined in Section 1 and is equal to $\mathrm{PX} *$ in the hypergeometric table.

The probability that the largest among $\mathrm{n}$ past observations will be exceeded $\mathrm{X}$ times or less in $\mathrm{m}$ future trials is given by $\operatorname{Pr}\{\mathrm{X}$ or less among $\mathrm{m}$ future trials will exceed the largest among $\mathrm{n}$ observations $\}$

$$
=\sum_{y=0}^{x}\left(\begin{array}{c}
m+n-y-1 \\
n-1
\end{array}\right) /\left(\begin{array}{c}
m+n \\
n
\end{array}\right)=1-\left(\begin{array}{c}
m+n-1-x \\
n
\end{array}\right) /\left(\begin{array}{c}
m+n \\
n
\end{array}\right) .
$$

The summation of the binomial coefficients was accomplished by means of Equation 12. 6 (page 61) of Reference 2. Hence, the

$\operatorname{Pr}\{\mathrm{X}$ or less among $\mathrm{m}$ future trials will exceed the largest among $\mathrm{n}$ observations $\}$

$$
=1-P *\{m+n, n, X+1,0\}, \text { for } 0 \leq X \leq m \text {, }
$$

and

$\operatorname{Pr}\{\mathrm{X}$ or more among $\mathrm{m}$ future trials will exceed the largest among $\mathrm{n}$ observations $\}$

$$
=P *\{m+n, n, X, 0\}, \text { for } 0 \leq X \leq m \text {. }
$$

Also,

$$
\begin{aligned}
& \operatorname{Pr}\{\mathrm{X} \text { or less among } \mathrm{m} \text { future trials will exceed } \\
& \text { the smallest observation in a sample of } n\}
\end{aligned}
$$$$
=\sum_{y=0}^{X}\left(\begin{array}{c}
y+n-1 \\
n-1
\end{array}\right) /\left(\begin{array}{c}
m+n \\
n
\end{array}\right)=\left(\begin{array}{c}
n+x \\
n
\end{array}\right) /\left(\begin{array}{c}
m+n \\
n
\end{array}\right) .
$$

The summation of the binomial coefficients was accomplished by means of Equation 12.8 (page 62) of Reference 2 . 
Then,

$$
\begin{aligned}
& \text { Pr }\{\mathrm{X} \text { or less among } \mathrm{m} \text { future trials will exceed } \\
& \text { the smallest observation in a sample of } n\} \\
& =P *\{m+n, n, m-X, 0\}, \text { for } 0 \leq x \leq m \text {. }
\end{aligned}
$$

Consider the following example of the use of the hypergeometric table. What is the probability that the largest flood in the past 20 years will be exceeded at least once during the next 25 years?

The answer is (assuming no major change in weather patterns)

Pr\{one or more among 25 future years will have a flood which exceeds the largest flood in the past 20 years\}

$$
=P *\{45,20,1,0\}=0.55556 \text {. }
$$

It is also possible to list the probability of $\mathrm{X}$ or more exceedances for all values of $X, 0 \leq X \leq 25$. These are

$$
\begin{aligned}
& P *\{45,20,0,0\}=1.00000 \\
& P *\{45,20,1,0\}=0.55556 \\
& P *\{45,20,2,0\}=0.30303 \\
& P *\{45,20,3,0\}=0.16209 \\
& P *\{45,20,4,0\}=0.08490 \\
& P *\{45,20,5,0\}=0.04349 \\
& P *\{45,20,6,0\}=0.02174 \\
& P *\{45,20,7,0\}=0.01059 \\
& P *\{45,20,8,0\}=0.00502 \\
& P *\{45,20,9,0\}=0.00231 \\
& P *\{45,20,10,0\}=0.00102 \\
& P *\{45,20,11,0\}=0.00044 \\
& P *\{45,20,12,0\}=0.00018 \\
& P *\{45,20,13,0\}=0.00007 \\
& P *\{45,20,14,0\}=0.00003 \\
& P *\{45,20,15,0\}=0.00001
\end{aligned}
$$


and the rest of the probabilities are zero to five decimal places. Using this table makes it possible to pick a value of $X$ such that the probability of $X$ or more exceedances is less than some set probability.

As a second example, consider the following. In a sample of 15 of the SA-2's, all met a certain criterion on voltage; i.e., all were below a stated voltage. What is the probability that in an additional sample of 20 all will also be below the stated voltage?

The method given here gives the following bound on the required probability: $\operatorname{Pr}\{$ zero among 20 future trials will exceed the largest among 15 observations $\}$

$$
=1-P *\{35,15,1,0\}=1-0.57142849=0.42857151 \text {. }
$$

The probability requested is less than this value; i.e.,

Pr\{all observations in the second sample will be below the stated voltage $\} \leq 0.42857151$.

For a probability like this to be small, the first sample must be large compared to the second sample.

As a third example, what is the probability that one additional observation from a population will be between the extremes of a sample of size $n$ ? The answer is obtained by specializing the following:

$$
\begin{aligned}
& \operatorname{Pr}\{\mathrm{X} \text { or more among } \mathrm{m} \text { future trials will exceed } \\
& \text { the largest among } \mathrm{n} \text { observations }\} \\
& \quad=\mathrm{P} *\{\mathrm{~m}+\mathrm{n}, \mathrm{n}, \mathrm{X}, 0\} \text { for } 0 \leq \mathrm{X} \leq \mathrm{m} .
\end{aligned}
$$

For the problem at hand, $\mathrm{X}=1$ and $\mathrm{m}=1$ and, because of symmetry,

$$
\text { Pr\{one future trial will be below the smallest among } n \text { observations }\}
$$

$$
=P *\{n+1, n, 1,0\} \text { also. }
$$

Hence,

$$
\begin{aligned}
& \text { Prfone additional observation will be between } \\
& \text { the extremes of a sample of size } n\} \\
& =1-2 P^{*}\{n+1, n, 1,0\}=1-\frac{2}{n+1}=\frac{n-1}{n+1} .
\end{aligned}
$$

Another question can now be answered from this last equation. That is, how large a sample is needed to be 95 -percent sure that the next observation is between the extremes of the sample? The answer is obtained from 


$$
\frac{n-1}{n+1}=0.95
$$

or

$$
\mathrm{n}=39 \text {. }
$$

It is interesting to compare this result with distribution-free tolerance limits. Using Table IV (page 11) of Reference 6 makes it possible to say with 95-percent confidence that at least 88.37 percent of the future observations will lie between the extremes. of the sample.

\section{Applications to a Sequential Procedure}

Given a lot of $\mathrm{N}$ items containing $\mathrm{k}$ defectives, a frequent question is: how many items must be sampled from the lot to produce $n$ nondefectives?

The solution to this problem may be obtained as follows:

$$
\begin{aligned}
& \operatorname{Pr}\{\mathrm{X}+\mathrm{n} \text { trials or less will be required to produce } \mathrm{n} \text { nondefectives }\} \\
& =\frac{(\mathrm{N}-\mathrm{k}) !(\mathrm{N}-\mathrm{n}) !}{(\mathrm{N}-\mathrm{k}-\mathrm{n}) ! \mathrm{N} !}\left[1+\mathrm{n} \frac{\mathrm{k}}{\mathrm{N}-\mathrm{n}}+\frac{\mathrm{n}(\mathrm{n}+1)}{2} \frac{\mathrm{k}(\mathrm{k}-1)}{(\mathrm{N}-\mathrm{n})(\mathrm{N}-\mathrm{n}-1)}+\ldots\right. \\
& \left.+\frac{\mathrm{n}(\mathrm{n}+1) \ldots(\mathrm{n}+\mathrm{X}-1)}{\mathrm{X} !} \frac{\mathrm{k}(\mathrm{k}-1) \ldots(\mathrm{k}-\mathrm{X}+1)}{(\mathrm{N}-\mathrm{n})(\mathrm{N}-\mathrm{n}-1) \ldots(\mathrm{N}-\mathrm{n}-\mathrm{X}+1)}\right]
\end{aligned}
$$

where $0 \leq \mathrm{X} \leq \mathrm{k}$ and $\mathrm{N} \geq \mathrm{k}+\mathrm{n}$.

Now by an argument exactly equivalent to the argument which connects negative binomial sums to binomial sums given in Appendix A of Reference 7 , it can be shown that this probability reduces to

$$
1-P\{N, X+n, N-k, n-1\}=P\{N, n+X, k, X\} .
$$

For example, suppose a lot of 50 items contains 10 defectives and it is necessary to obtain 20 nondefective items from the lot. The sampling will stop when the 20 nondefectives are obtained. What is the probability that the 20 nondefective items can be obtained with a sample of 25 or less?

The answer is $\mathrm{P}\{50,25,10,5\}=0.63739897$.

The entire probability distribution for the possible sample sizes may be obtained from the hypergeometric table also. The distribution is

Sample size

20

21

22

\section{Look up}

$$
\begin{aligned}
& P\{50,20,10,0\}=0.00292486 \\
& P\{50,21,10,1\}=0.02242396 \\
& P\{50,22,10,2\}=0.08596408
\end{aligned}
$$


Sample size

23

24

25

26

27

28

29

30
Look up

$\mathrm{P}\{50,23,10,3\}=0.21909597$

$\mathrm{P}\{50,24,10,4\}=0.41756099$

$\mathrm{P}\{50,25,10,5\}=0.63739897$

$P\{50,26,10,6\}=0.82059771$

$P\{50,27,10,7\}=0.93400604$

$\mathrm{P}\{50,28,10,8\}=0.98393041$

$P\{50,29,10,9\}=0.99805093$

$\mathrm{P}\{50,30,10,10\}=1.00000000$

Hence, for example, about 66 times out of 1000 it will be necessary to take a sample of 27 to obtain 20 nondefectives from the lot.

As a second example, suppose a lot of $\mathrm{N}=35$ items is at hand, and it is necessary to obtain 20 nondefectives from this lot and then sampling will cease. When sampling is stopped, it is necessary to make a statement about the number of defectives in the original lot; e.g., the number of defectives in the lot is no more than $\mathrm{k}$ with 90 -percent assurance.

This problem may be solved by solving $P\{35, X+20, k, X\} \leq 0.10$ for $k$. The results are:

\begin{tabular}{|c|c|c|c|}
\hline Sample size taken & $\underline{X}$ & $\underline{\mathrm{k}}$ & Actual proba \\
\hline 20 & 0 & 3 & 0.070 \\
\hline 21 & 1 & 5 & 0.071 \\
\hline 22 & 2 & 7 & 0.050 \\
\hline 23 & 3 & 8 & 0.070 \\
\hline 24 & 4 & 9 & 0.084 \\
\hline 25 & 5 & 10 & 0.089 \\
\hline 26 & 6 & 11 & 0.084 \\
\hline 27 & 7 & 12 & 0.070 \\
\hline 28 & 8 & 13 & 0.050 \\
\hline 29 & 9 & 14 & 0.028 \\
\hline 30 & 10 & 14 & 0.070 \\
\hline 31 & 11 & 15 & 0.026 \\
\hline 32 & 12 & 15 & 0.070 \\
\hline
\end{tabular}

Now, for example, it can be said that if sampling stopped with a sample of 25 items to produce 20 nondefective items, one is at least 90 -percent sure that 
there were no more than 10 defective items in the lot before sampling; or equivalently, one is 90 -percent sure that there are no more than five defective items in the remaining ten items.

It might be instructive to compare these results with the case of an infinite lot. Suppose a sample of 25 is taken from a continuous production process to produce 20 nondefective items. With 90 -percent assurance, what is the upper bound on the proportion defective coming from this process?

The answer is obtained by using Section 9 of Reference 7 (page 12) and is given by

$$
1-\frac{n+1}{n+1+X F_{\gamma, 2 X}, 2 n+2}
$$

where $F_{\gamma}$ is an upper $\gamma$-percentage point of the $F$ distribution based on $2 \mathrm{X}$ degrees of freedom for the numerator, and $2 n+2$ degrees of freedom for the denominator. Here $n=20$ and $X=5$, and hence $F_{0.90}=1.75$, and the upper bound on the proportion defective produced by the process is $1-0.706=0.294$, with 90 -percent assurance. For the finite lot with $\mathrm{N}=35$, as pointed out above, the proportion defective in the original lot is less than $10 / 35=0.286$ with 90 -percent assurance, or the proportion defective in the remaining part of the lot is less than $5 / 10=0.500$ with 90 -percent assurance.

\section{Number of Entries in the Table}

In this section a formula for the number of entries in the table as presently constructed is derived, then a second formula is given for determining the number of entries if all the symmetry mentioned in Section 1 is used.

If all of the sets of entries began with $X$ equal to zero, i. e., the counts started with zero even when they should have started with $N^{*}+K^{*}-N$, then the number of entries would be

$$
S_{1}=\sum_{N=2}^{p} \sum_{N^{*}=1}^{N-1} \sum_{K^{*}=1}^{N-N^{*}} \sum_{X=0}^{K *} 1=\frac{(p-1) p(p+1)(p+6)}{24},
$$

where $\mathrm{p}$ is the last value of $\mathrm{N}$ that is to be included in the table and all possible entries in the hypergeometric table are included except those for which $\mathrm{K}^{*}>\mathrm{N}^{*}$. 
But all of the sets of entries did not start at zero, and the number of entries to be subtracted is

$$
S_{2}=\sum_{N} \sum_{N^{*}} \sum_{K^{*}=N^{*}-N^{*}+1}^{N^{*}} \sum_{X=0}^{N^{*}+\mathrm{K}^{*}-\mathrm{N}-1} 1
$$

If $N$ is even, $N^{*}$ goes from $\frac{N}{2}+1$ to $N-1$; and if $N$ is odd, $N^{*}$ goes from $\frac{N+1}{2}$ to $\mathrm{N}-1$.

For just the even values of $N$, part of $S_{2}$ reduces to (with $N=2 R$ )

$$
S_{3}=\sum_{R=2}^{M} \sum_{N *=R+1}^{2 R-1}\left(2 N *^{2}+N *-2 N * N-R+2 R^{2}\right)=\frac{M(M-1)(M+1)^{2}}{6} . .
$$

For just the odd values of $N$, part of $S_{2}$ reduces to (with $N=2 R+1$ )

$$
S_{4}=\sum_{R=1}^{Q} \sum_{N *=R+1}^{2 R}\left(2 N *^{2}+N *-4 N * R-2 N *+2 R^{2}+R\right)=\frac{Q^{2}(Q+1)(Q+2)}{6}
$$

Now if $\mathrm{p}$ is even, then the number of entries is obtained by taking $\mathrm{S}_{1}$ and subtracting $\mathrm{S}_{3}^{\prime}$ and $\mathrm{S}_{4}^{\prime}$,

where

$$
S_{3}^{\prime}=\frac{p(p-2)(p+2)^{2}}{96}
$$

and

$$
S_{4}^{\prime}=\frac{(p-2)^{2} p(p+2)}{96} .
$$

Hence,

$$
S=\frac{p\left(p^{3}+12 p^{2}+2 p-12\right)}{48}
$$

for even values of $p$.

Similarly, for odd values of $p$,

$$
S_{3}^{\prime \prime}=\frac{(p-3)(p-1)(p+1)^{2}}{96},
$$

and

$$
S_{4}^{\prime \prime}=\frac{(p-1)^{2}(p+1)(p+3)}{96}
$$

Hence,

$$
S=\frac{p^{4}+12 p^{3}+2 p^{2}-12 p-3}{48}
$$

for odd values of $\mathrm{p}$. 
For example, if $p=50, S=161,550$ entries, and since there are 50 entries per page, there are 3231 pages in the table up through $\mathrm{N}=50$.

If $p=37, S=51,756$, and since there are 50 entries per page, there are 1035 pages plus six entries in the table up through $\mathrm{N}=37$.

In summary, the number of entries in the table may be obtained from

$$
S=\frac{p^{4}+12 p^{3}+2 p^{2}-12 p-\left\{\begin{array}{l}
0 \\
3
\end{array}\right.}{48}
$$

where the 0 is used if $p$ is even, the 3 is used if $p$ is odd, and $p$ is the last value of $\mathrm{N}$ to be included in the table.

If the additional symmetries of the hypergeometric function mentioned in Section 1 are used, it is possible to restrict $N^{*}$ as follows:

$$
\mathrm{K}^{*} \leq \mathrm{N} * \leq \mathrm{N} / 2 \text {. }
$$

Note that now all the X's start at zero.

Then the number of items in the table becomes

$$
S^{*}=\sum_{N=2}^{p} \sum_{N^{*}=1}^{[N / 2]} \sum_{K^{*}=1}^{N *} \sum_{X=0}^{K *} 1 \text {, }
$$

where the bracket indicates the greatest integer less than or equal to N/2.

Then,

$$
S^{*}=\sum_{N=2}^{p} \sum_{N *=1}^{[N / 2]} \sum_{K *=1}^{N *}\left(K^{*}+1\right)=\sum_{N=2}^{p} \sum_{N *=1}^{[N / 2]} \frac{N *(N *+3)}{2} .
$$

If $N=2 R$,

$$
S_{1}^{*}=\sum_{N=2}^{p} \sum_{N *=1}^{R} \frac{1}{2}\left(N *^{2}+3 N *\right)=\sum_{N=2}^{p} \frac{R(R+1)(R+5)}{6} .
$$

If $N=2 Q+1$,

$$
S_{2}^{*}=\sum_{N=2}^{p} \sum_{N *=1}^{Q} \frac{1}{2}\left(N^{*}+3 N *\right)=\sum_{N=2}^{p} \frac{Q(Q+1)(Q+5)}{6} .
$$

Now if $p=2 s$,

$$
\begin{aligned}
S * & =\sum_{R=1}^{S} \frac{R(R+1)(R+5)}{6}+\sum_{Q=1}^{S-1} \frac{Q(Q+1)(Q+5)}{6} \\
& =\frac{1}{24}[s(s+1)(s+2)(s+7)+(s-1) s(s+1)(s+6)] \\
& =\frac{1}{12}\left[s(s+1)\left(s^{2}+7 s+4\right)\right]
\end{aligned}
$$


hence, if $p$ is even,

$$
S *=\frac{1}{192}\left[p(p+2)\left(p^{2}+14 p+16\right)\right]
$$

If $p=2 s+1$,

$$
S *=\sum_{R=1}^{S} \frac{R(R+1)(R+5)}{6}+\sum_{Q=1}^{S} \frac{Q(Q+1)(Q+5)}{6}=\frac{1}{12}[s(s+1)(s+2)(s+7)] ;
$$

and hence if $\mathrm{p}$ is odd,

$$
S *=\frac{1}{192}[(p-1)(p+1)(p+3)(p+13)] .
$$

In summary, if all the symmetry of the hypergeometric function is used,

$$
S *=\frac{1}{192}\left[p(p+2)\left(p^{2}+14 p+16\right)\right] \text { for even values of } p \text {, }
$$

and

$$
S^{*}=\frac{1}{192}[(p-1)(p+1)(p+3)(p+13)] \text { for odd values of } p
$$

If $p=50, S^{*}=43,550$ entries, or 871 pages at 50 entries per page; and for $p=100$, $S^{*}=606,475$ entries, or $12,129.5$ pages at 50 entries per page. 
APPENDIX

22101 
Sample Pages from the Hypergeometric Table

\begin{tabular}{|c|c|c|c|c|c|}
\hline $\mathbf{N}$ & $\mathrm{N*}$ & $K^{*}$ & $\mathrm{X}$ & PX & PX* \\
\hline 2 & 1 & 1 & 0 & 0.50000000 & 0.50000000 \\
\hline 2 & 1 & 1 & 1 & 1.00000000 & 0.50000000 \\
\hline 3 & 1 & 1 & 0 & 0.66666666 & 0.66666666 \\
\hline 3 & 1 & 1 & 1 & 0.99999999 & 0.33333332 \\
\hline 3 & 2 & 1 & 0 & 0.33333332 & 0.33333332 \\
\hline 3 & 2 & 1 & 1 & 0.99999999 & 0.66666666 \\
\hline 3 & 2 & 2 & 1 & 0.66666666 & 0.66666666 \\
\hline 3 & 2 & 2 & 2 & 0.99999999 & 0.33333332 \\
\hline 4 & 1 & 1 & 0 & 0.74999999 & 0.74999999 \\
\hline 4 & 1 & 1 & 1 & 0.99999999 & 0.25000000 \\
\hline 4 & 2 & 1 & 0 & 0.50000000 & 0.50000000 \\
\hline 4 & 2 & 1 & 1 & 1.00000000 & 0.50000000 \\
\hline 4 & 2 & 2 & 0 & 0.16666666 & 0.16666666 \\
\hline 4 & 2 & 2 & 1 & 0.83333332 & 0.66666666 \\
\hline 4 & 2 & 2 & 2 & 0.99999998 & 0.16666666 \\
\hline 4 & 3 & 1 & 0 & 0.25000000 & 0.25000000 \\
\hline 4 & 3 & 1 & 1 & 0.99999999 & 0.74999999 \\
\hline 4 & 3 & 2 & 1 & 0.50000000 & 0.50000000 \\
\hline 4 & 3 & 2 & 2 & 1.00000000 & 0.50000000 \\
\hline 4 & 3 & 3 & 2 & 0.75000002 & 0.75000002 \\
\hline 4 & 3 & 3 & 3 & 1.00000001 & 0.25000000 \\
\hline 5 & 1 & 1 & 0 & 0.79999999 & 0.79999999 \\
\hline 5 & 1 & 1 & 1 & 0.99999999 & 0.20000000 \\
\hline 5 & 2 & 1 & 0 & 0.59999999 & 0.59999999 \\
\hline 5 & 2 & 1 & 1 & 0.99999996 & 0.39999997 \\
\hline 5 & 2 & 2 & 0 & 0.29999999 & 0.29999999 \\
\hline 5 & 2 & 2 & 1 & 0.89999995 & 0.59999996 \\
\hline 5 & 2 & 2 & 2 & 0.99999993 & 0.09999998 \\
\hline 5 & 3 & 1 & 0 & 0.39999995 & 0.39999995 \\
\hline 5 & 3 & 1 & 1 & 0.99999995 & 0.59999999 \\
\hline 5 & 3 & 2 & 0 & 0.09999996 & 0.09999996 \\
\hline 5 & 3 & 2 & 1 & 0.69999993 & 0.59999996 \\
\hline 5 & 3 & 2 & 2 & 0.99999992 & 0.29999999 \\
\hline 5 & 3 & 3 & 1 & 0.29999999 & 0.29999999 \\
\hline 5 & 3 & 3 & 2 & 0.89999995 & 0.59999996 \\
\hline 5 & 3 & 3 & 3 & 0.99999992 & 0.09999996 \\
\hline 5 & 4 & 1 & 0 & 0.19999997 & 0.19999997 \\
\hline 5 & 4 & 1 & 1 & 0.99999992 & 0.79999995 \\
\hline 5 & 4 & 2 & 1 & 0.39999992 & 0.39999992 \\
\hline 5 & 4 & 2 & 2 & 0.99999992 & 0.59999999 \\
\hline 5 & 4 & 3 & 2 & 0.59999999 & 0.59999999 \\
\hline 5 & 4 & 3 & 3 & 0.99999992 & 0.39999992 \\
\hline 5 & 4 & 4 & 3 & 0.79999991 & 0.79999991 \\
\hline 5 & 4 & 4 & 4 & 0.99999987 & 0.19999997 \\
\hline
\end{tabular}


Sample Pages from the Hypergeometric Table (continued)

\begin{tabular}{|c|c|c|c|c|c|}
\hline $\mathbf{N}$ & $N *$ & $\mathrm{~K}^{*}$ & $\mathrm{X}$ & PX & PX* \\
\hline 6 & 1 & 1 & 0 & 0.83333333 & 0.83333333 \\
\hline 6 & 1 & 1 & 1 & 0.99999999 & 0.16666666 \\
\hline 6 & 2 & 1 & 0 & 0.66666666 & 0.66666666 \\
\hline 6 & 2 & 1 & 1 & 0.99999999 & 0.33333332 \\
\hline 6 & 2 & 2 & 0 & 0.39999997 & 0. 39999997 \\
\hline 6 & 2 & 2 & 1 & 0.93333327 & 0.53333330 \\
\hline 6 & 2 & 2 & 2 & 0.99999993 & 0.06666666 \\
\hline 6 & 3 & 1 & 0 & 0.50000000 & 0.50000000 \\
\hline 6 & 3 & 1 & 1 & 1.00000000 & 0.50000000 \\
\hline 6 & 3 & 2 & 0 & 0.20000000 & 0.20000000 \\
\hline 6 & 3 & 2 & 1 & 0.80000000 & 0.59999999 \\
\hline 6 & 3 & 2 & 2 & 1.00000000 & 0.20000000 \\
\hline 6 & 3 & 3 & 0 & 0.05000000 & 0.05000000 \\
\hline 6 & 3 & 3 & 1 & 0.50000000 & 0.45000000 \\
\hline 6 & 3 & 3 & 2 & 0.95000000 & 0.45000000 \\
\hline 6 & 3 & 3 & 3 & 1.00000000 & 0.05000000 \\
\hline 6 & 4 & 1 & 0 & 0.33333332 & 0.33333332 \\
\hline 6 & 4 & 1 & 1 & 0.99999999 & 0.66666666 \\
\hline 6 & 4 & 2 & 0 & 0.06666664 & 0.06666664 \\
\hline 6 & 4 & 2 & 1 & 0.59999994 & 0.53333330 \\
\hline 6 & 4 & 2 & 2 & 0.99999990 & 0.39999995 \\
\hline 6 & 4 & 3 & 1 & 0.19999997 & 0.19999997 \\
\hline 6 & 4 & 3 & 2 & 0.79999996 & 0.59999999 \\
\hline 6 & 4 & 3 & 3 & 0.99999993 & 0.19999997 \\
\hline 6 & 4 & 4 & 2 & 0.39999995 & 0.39999995 \\
\hline 6 & 4 & 4 & 3 & 0.93333314 & 0.53333319 \\
\hline 6 & 4 & 4 & 4 & 0.99999978 & 0.06666664 \\
\hline 6 & 5 & 1 & 0 & 0.16666666 & 0.16666656 \\
\hline 6 & 5 & 1 & 1 & 1.00000004 & 0.83333340 \\
\hline 6 & 5 & 2 & 1 & 0.33333327 & 0.33333327 \\
\hline 6 & 5 & 2 & 2 & 0.99999991 & 0.66666664 \\
\hline 6 & 5 & 3 & 2 & 0.50000004 & 0.50000004 \\
\hline 6 & 5 & 3 & 3 & 1.00000009 & 0.50000004 \\
\hline 6 & 5 & 4 & 3 & 0.66666664 & 0.66666664 \\
\hline 6 & 5 & 4 & 4 & 0.99999991 & 0.33333327 \\
\hline 6 & 5 & 5 & 4 & 0.83333340 & 0.83333340 \\
\hline 6 & 5 & 5 & 5 & 1.00000004 & 0.16666666 \\
\hline 7 & 1 & 1 & 0 & 0.85714285 & 0.85714285 \\
\hline 7 & 1 & 1 & 1 & 0.99999996 & 0.14285711 \\
\hline 7 & 2 & 1 & 0 & 0.71428570 & 0.71428570 \\
\hline 7 & 2 & 1 & 1 & 0.99999998 & 0.28571428 \\
\hline 7 & 2 & 2 & 0 & 0.47619046 & 0.47619046 \\
\hline 7 & 2 & 2 & 1 & 0.95238090 & 0.47619043 \\
\hline 7 & 2 & 2 & 2 & 0.99999993 & 0.04761904 \\
\hline 7 & 3 & 1 & 0 & 0.57142854 & 0.57142854 \\
\hline 7 & 3 & 1 & 1 & 0.99999997 & 0.42857143 \\
\hline 7 & 3 & 2 & 0 & 0.28571428 & 0.28571428 \\
\hline 7 & 3 & 2 & 1 & 0.85714281 & 0.57142854 \\
\hline 7 & 3 & 2 & 2 & 0.99999993 & 0.14285711 \\
\hline
\end{tabular}

$$
221 \quad 023
$$


Sample Pages from the Hypergeometric Table (continued)

\begin{tabular}{|c|c|c|c|c|c|}
\hline $\mathrm{N}$ & $N^{*}$ & $\mathrm{~K}^{*}$ & $\mathrm{X}$ & $\mathrm{PX}$ & PX* \\
\hline 7 & 3 & 3 & 0 & 0.11428571 & 0.11428571 \\
\hline 7 & 3 & 3 & 1 & 0.62857142 & 0.51428571 \\
\hline 7 & 3 & 3 & 2 & 0.97142854 & 0.34285712 \\
\hline 7 & 3 & 3 & 3 & 0.99999997 & 0.02857143 \\
\hline 7 & 4 & 1 & 0 & 0.42857143 & 0.42857143 \\
\hline 7 & 4 & 1 & 1 & 0.99999997 & 0.57142854 \\
\hline 7 & 4 & 2 & 0 & 0.14285713 & 0.14285713 \\
\hline 7 & 4 & 2 & 1 & 0.71428566 & 0.57142854 \\
\hline 7 & 4 & 2 & 2 & 0.99999998 & 0.28571431 \\
\hline 7 & 4 & 3 & 0 & 0.02857143 & 0.02857143 \\
\hline 7 & 4 & 3 & 1 & 0.37142855 & 0.34285712 \\
\hline 7 & 4 & 3 & 2 & 0.88571428 & 0.51428573 \\
\hline 7 & 4 & 3 & 3 & 0.99999999 & 0.11428571 \\
\hline 7 & 4 & 4 & 1 & 0.11428571 & 0.11428571 \\
\hline 7 & 4 & 4 & 2 & 0.62857144 & 0.51428573 \\
\hline 7 & 4 & 4 & 3 & 0.97142856 & 0.34285712 \\
\hline 7 & 4 & 4 & 4 & 0.99999999 & 0.02857143 \\
\hline 7 & 5 & 1 & 0 & 0.28571428 & 0.28571428 \\
\hline 7 & 5 & 1 & 1 & 1.00000004 & 0.71428578 \\
\hline 7 & 5 & 2 & 0 & 0.04761904 & 0.04761904 \\
\hline 7 & 5 & 2 & 1 & 0.52380948 & 0.47619043 \\
\hline 7 & 5 & 2 & 2 & 0.99999996 & 0.47619049 \\
\hline 7 & 5 & 3 & 1 & 0.14285713 & 0.14285713 \\
\hline 7 & 5 & 3 & 2 & 0.71428566 & 0.57142854 \\
\hline 7 & 5 & 3 & 3 & 0.99999998 & 0.28571431 \\
\hline 7 & 5 & 4 & 2 & 0.28571431 & 0.28571431 \\
\hline 7 & 5 & 4 & 3 & 0.85714285 & 0.57142854 \\
\hline 7 & 5 & 4 & 4 & 0.99999998 & 0.14285713 \\
\hline 7 & 5 & 5 & 3 & 0.47619043 & 0.47619043 \\
\hline 7 & 5 & 5 & 4 & 0.95238087 & 0.47619043 \\
\hline 7 & 5 & 5 & 5 & 0.99999991 & 0.04761904 \\
\hline 7 & 6 & 1 & 0 & 0.14285713 & 0.14285713 \\
\hline 7 & 6 & 1 & 1 & 1.00000001 & 0.85714289 \\
\hline 7 & 6 & 2 & 1 & 0.28571428 & 0.28571428 \\
\hline 7 & 6 & 2 & 2 & 1.00000004 & 0.71428578 \\
\hline 7 & 6 & 3 & 2 & 0.42857146 & 0.42857146 \\
\hline 7 & 6 & 3 & 3 & 1.00000000 & 0.57142854 \\
\hline 7 & 6 & 4 & 3 & 0.57142849 & 0.57142849 \\
\hline 7 & 6 & 4 & 4 & 0.99999996 & 0.42857146 \\
\hline 7 & 6 & 5 & 4 & 0.71428578 & 0.71428578 \\
\hline 7 & 6 & 5 & 5 & 1.00000004 & 0.28571428 \\
\hline 7 & 6 & 6 & 5 & 0.85714289 & 0.85714289 \\
\hline 7 & 6 & 6 & 6 & 1.00000001 & 0.14285713 \\
\hline 8 & 1 & 1 & 0 & 0.87500001 & 0.87500001 \\
\hline 8 & 1 & 1 & 1 & 0.99999999 & 0.12499998 \\
\hline 8 & 2 & 1 & 0 & 0.74999999 & 0.74999999 \\
\hline 8 & 2 & 1 & 1 & 0.99999999 & $0: 25000000$ \\
\hline 8 & 2 & 2 & 0 & 0.53571426 & 0.53571426 \\
\hline
\end{tabular}


Sample Pages from the Hypergeometric Table (continued)

\begin{tabular}{|c|c|c|c|c|c|}
\hline $\mathrm{N}$ & N* & $\mathrm{K} *$ & $\mathrm{x}$ & PX & $\mathrm{PX}^{*}$ \\
\hline 8 & 2 & 2 & 1 & 0.96428566 & 0.42857140 \\
\hline 8 & 2 & 2 & 2 & 0.99999993 & 0.03571428 \\
\hline 8 & 3 & 1 & 0 & 0.62499999 & 0.62499999 \\
\hline 8 & 3 & 1 & 1 & 0.99999996 & 0.37499998 \\
\hline 8 & 3 & 2 & 0 & 0.35714284 & 0.35714284 \\
\hline 8 & 3 & 2 & 1 & 0.89285710 & 0.53571426 \\
\hline 8 & 3 & 2 & 2 & 0.99999993 & 0.10714284 \\
\hline 8 & 3 & 3 & 0 & 0.17857145 & 0.17857145 \\
\hline 8 & 3 & 3 & 1 & 0.71428574 & 0.53571429 \\
\hline 8 & 3 & 3 & 2 & 0.98214288 & 0.26785714 \\
\hline 8 & 3 & 3 & 3 & 1.00000000 & 0.01785713 \\
\hline 8 & 4 & 1 & 0 & 0.49999997 & 0.49999997 \\
\hline 8 & 4 & 1 & 1 & 0.99999994 & 0.49999997 \\
\hline 8 & 4 & 2 & 0 & 0.21428568 & 0.21428568 \\
\hline 8 & 4 & 2 & 1 & 0.78571417 & 0.57142849 \\
\hline 8 & 4 & 2 & 2 & 0.99999985 & 0.21428568 \\
\hline 8 & 4 & 3 & 0 & 0.07142855 & 0.07142855 \\
\hline 8 & 4 & 3 & 1 & 0.49999999 & 0.42857143 \\
\hline 8 & 4 & 3 & 2 & 0.92857142 & 0.42857143 \\
\hline 8 & 4 & 3 & 3 & 0.99999997 & 0.07142855 \\
\hline 8 & 4 & 4 & 0 & 0.01428570 & 0.01428570 \\
\hline 8 & 4 & 4 & 1 & 0.24285707 & 0.22857137 \\
\hline 8 & 4 & 4 & 2 & 0.75714278 & 0.51428571 \\
\hline 8 & 4 & 4 & 3 & 0.98571415 & 0.22857137 \\
\hline 8 & 4 & 4 & 4 & 0.99999985 & 0.01428570 \\
\hline 8 & 5 & 1 & 0 & 0.37499999 & 0.37499999 \\
\hline 8 & 5 & 1 & 1 & 1. 00000000 & 0.62500001 \\
\hline 8 & 5 & 2 & 0 & 0.10714284 & 0.10714284 \\
\hline 8 & 5 & 2 & 1 & 0.64285713 & 0.53571429 \\
\hline 8 & 5 & 2 & 2 & 0.99999996 & 0.35714284 \\
\hline 8 & 5 & 3 & 0 & 0.01785713 & 0.01785713 \\
\hline 8 & 5 & 3 & 1 & 0.28571427 & 0.26785714 \\
\hline 8 & 5 & 3 & 2 & 0.82142860 & 0.53571434 \\
\hline 8 & 5 & 3 & 3 & 1.00000004 & 0.17857145 \\
\hline 8 & 5 & 4 & 1 & 0.07142854 & 0.07142854 \\
\hline 8 & 5 & 4 & 2 & 0.49999997 & 0.42857143 \\
\hline 8 & 5 & 4 & 3 & 0.92857140 & 0.42857143 \\
\hline 8 & 5 & 4 & 4 & 0.99999994 & 0.07142854 \\
\hline 8 & 5 & 5 & 2 & 0.17857143 & 0.17857143 \\
\hline 8 & 5 & 5 & 3 & 0.71428569 & 0.53571426 \\
\hline 8 & 5 & 5 & 4 & 0.98214282 & 0.26785713 \\
\hline 8 & 5 & 5 & 5 & 0.99999995 & 0.01785713 \\
\hline 8 & 6 & 1 & 0 & 0.24999997 & 0.24999997 \\
\hline 8 & 6 & 1 & 1 & 0.99999994 & 0.74999997 \\
\hline 8 & 6 & 2 & 0 & 0.03571428 & 0.03571428 \\
\hline 8 & 6 & 2 & 1 & 0.46428562 & 0.42857134 \\
\hline 8 & 6 & 2 & 2 & 0.99999991 & 0.53571429 \\
\hline 8 & 6 & 3 & 1 & 0.10714284 & 0.10714284 \\
\hline 8 & 6 & 3 & 2 & 0.64285713 & 0.53571429 \\
\hline
\end{tabular}


Sample Pages from the Hypergeometric Table (continued)

\begin{tabular}{|c|c|c|c|c|c|}
\hline $\mathrm{N}$ & $N *$ & $\mathrm{~K}^{*}$ & $\mathrm{x}$ & PX & PX* \\
\hline 8 & 6 & 3 & 3 & 0.99999996 & 0.35714284 \\
\hline 8 & 6 & 4 & 2 & 0.21428566 & 0.21428566 \\
\hline 8 & 6 & 4 & 3 & 0.78571402 & 0.57142836 \\
\hline 8 & 6 & 4 & 4 & 0.99999967 & 0.21428566 \\
\hline 8 & 6 & 5 & 3 & 0.35714277 & 0.35714277 \\
\hline 8 & 6 & 5 & 4 & 0.89285703 & 0.53571426 \\
\hline 8 & 6 & 5 & 5 & 0.99999987 & 0.10714284 \\
\hline 8 & 6 & 6 & 4 & 0.53571426 & 0.53571426 \\
\hline 8 & 6 & 6 & 5 & 0.96428557 & 0.42857131 \\
\hline 8 & 6 & 6 & 6 & 0.99999985 & 0.03571428 \\
\hline 8 & 7 & 1 & 0 & 0.12499995 & 0.12499995 \\
\hline 8 & 7 & 1 & 1 & 0.99999988 & 0.87499993 \\
\hline 8 & 7 & 2 & 1 & 0.24999995 & 0.24999995 \\
\hline 8 & 7 & 2 & 2 & 0.99999987 & 0.74999992 \\
\hline 8 & 7 & 3 & 2 & 0,37499998 & 0.37499998 \\
\hline 8 & 7 & 3 & 3 & 0.99999994 & 0.62499996 \\
\hline 8 & 7 & 4 & 3 & 0.49999987 & 0.49999987 \\
\hline 8 & 7 & 4 & 4 & 0.99999975 & 0.49999987 \\
\hline 8 & 7 & 5 & 4 & 0.62499996 & 0.62499996 \\
\hline 8 & 7 & 5 & 5 & 0.99999994 & 0.37499998 \\
\hline 8 & 7 & 6 & 5 & 0.74999992 & 0.74999992 \\
\hline 8 & 7 & 6 & 6 & 0.99999987 & 0.24999995 \\
\hline 8 & 7 & 7 & 6 & 0.87499988 & 0.87499988 \\
\hline 8 & 7 & 7 & 7 & 0.99999983 & 0.12499995 \\
\hline 9 & 1 & 1 & 0 & 0.88888889 & 0.88888889 \\
\hline 9 & 1 & 1 & 1 & 0.99999999 & 0.11111110 \\
\hline 9 & 2 & 1 & 0 & 0.77777776 & 0.77777776 \\
\hline 9 & 2 & 1 & 1 & 0.99999997 & 0.22222221 \\
\hline 9 & 2 & 2 & 0 & 0.58333331 & 0.58333331 \\
\hline 9 & 2 & 2 & 1 & 0.97222216 & 0.38888886 \\
\hline 9 & 2 & 2 & 2 & 0.99999993 & 0.02777776 \\
\hline 9 & 3 & 1 & 0 & 0.66666666 & 0.66666666 \\
\hline 9 & 3 & 1 & 1 & 0.99999999 & 0.33333332 \\
\hline 9 & 3 & 2 & 0 & 0.41666666 & 0.41666666 \\
\hline 9 & 3 & 2 & 1 & 0.91666663 & 0.49999997 \\
\hline 9 & 3 & 2 & 2 & 0.99999995 & 0.08333332 \\
\hline 9 & 3 & 3 & 0 & 0.23809522 & 0.23809522 \\
\hline 9 & 3 & 3 & 1 & 0.77380951 & 0.53571429 \\
\hline 9 & 3 & 3 & 2 & 0.98809519 & 0.21428568 \\
\hline 9 & 3 & 3 & 3 & 0.99999995 & 0.01190475 \\
\hline 9 & 4 & 1 & 0 & 0.55555554 & 0.55555554 \\
\hline 9 & 4 & 1 & 1 & 0.99999999 & 0.44444444 \\
\hline 9 & 4 & 2 & 0 & 0.27777774 & 0.27777774 \\
\hline 9 & 4 & 2 & 1 & 0.83333325 & 0.55555551 \\
\hline 9 & 4 & 2 & 2 & 0.99999988 & 0.16666663 \\
\hline 9 & 4 & 3 & 0 & 0.11904762 & 0.11904762 \\
\hline 9 & 4 & 3 & 1 & 0.59523805 & 0.47619043 \\
\hline 9 & 4 & 3 & 2 & 9.95238093 & 0.35714287 \\
\hline 9 & 4 & 3 & 3 & 0.99999996 & 0.04761904 \\
\hline
\end{tabular}


Sample Pages from the Hypergeometric Table (continued)

\begin{tabular}{|c|c|c|c|c|c|}
\hline $\mathbf{N}$ & $N *$ & $\mathrm{~K}^{*}$ & $\mathrm{X}$ & $\mathrm{PX}$ & PX* \\
\hline 9 & 4 & 4 & 0 & 0.03968253 & 0.03968253 \\
\hline 9 & 4 & 4 & 1 & 0.35714284 & 0.31746031 \\
\hline 9 & 4 & 4 & 2 & 0.83333333 & 0.47619049 \\
\hline 9 & 4 & 4 & 3 & 0.99206348 & 0.15873015 \\
\hline 9 & 4 & 4 & 4 & 0.99999998 & 0.00793650 \\
\hline 9 & 5 & 1 & 0 & 0.44444441 & 0.44444441 \\
\hline 9 & 5 & 1 & 1 & 0.99999996 & 0.55555554 \\
\hline 9 & 5 & 2 & 0 & 0.16666663 & 0.16666663 \\
\hline 9 & 5 & 2 & 1 & 0.72222210 & 0.55555546 \\
\hline 9 & 5 & 2 & 2 & 0.99999984 & 0.27777774 \\
\hline 9 & 5 & 3 & 0 & 0.04761903 & 0.04761903 \\
\hline 9 & 5 & 3 & 1 & 0.40476190 & 0.35714287 \\
\hline 9 & 5 & 3 & 2 & 0.88095234 & 0.47619043 \\
\hline 9 & 5 & 3 & 3 & 0.99999996 & 0.11904762 \\
\hline 9 & 5 & 4 & 0 & 0.00793650 & 0.00793650 \\
\hline 9 & 5 & 4 & 1 & 0.16666662 & 0.15873012 \\
\hline 9 & 5 & 4 & 2 & 0.64285711 & 0.47619049 \\
\hline 9 & 5 & 4 & 3 & 0.96031742 & 0.31746031 \\
\hline 9 & 5 & 4 & 4 & 0.99999995 & 0.03968253 \\
\hline 9 & 5 & 5 & 1 & 0.03968253 & 0.03968253 \\
\hline 9 & 5 & 5 & 2 & 0.35714275 & 0.31746022 \\
\hline 9 & 5 & 5 & 3 & 0.83333316 & 0.47619040 \\
\hline 9 & 5 & 5 & 4 & 0.99206328 & 0.15873012 \\
\hline 9 & 5 & 5 & 5 & 0.99999978 & 0.00793650 \\
\hline 9 & 6 & 1 & 0 & 0.33333332 & 0.33333332 \\
\hline 9 & 6 & 1 & 1 & 0.99999996 & 0.66666664 \\
\hline 9 & 6 & 2 & 0 & 0.08333332 & 0.08333332 \\
\hline 9 & 6 & 2 & 1 & 0.58333327 & 0.49999995 \\
\hline 9 & 6 & 2 & 2 & 0.99999993 & 0.41666666 \\
\hline 9 & 6 & 3 & 0 & 0.01190475 & 0.01190475 \\
\hline 9 & 6 & 3 & 1 & 0.22619043 & 0.21428568 \\
\hline 9 & 6 & 3 & 2 & 0.76190477 & 0.53571434 \\
\hline 9 & 6 & 3 & 3 & 0.99999999 & 0.23809522 \\
\hline 9 & 6 & 4 & 1 & 0.04761903 & 0.04761903 \\
\hline 9 & 6 & 4 & 2 & 0.40476187 & 0.35714284 \\
\hline 9 & 6 & 4 & 3 & 0.88095227 & 0.47619040 \\
\hline 9 & 6 & 4 & 4 & 0.99999989 & 0.11904762 \\
\hline g & 6 & 5 & 2 & 0.11904762 & 0.11904762 \\
\hline 9 & 6 & 5 & 3 & 0.59523802 & 0.47619040 \\
\hline 9 & 6 & 5 & 4 & 0.95238086 & 0.35714284 \\
\hline 9 & 6 & 5 & 5 & 0.99999989 & 0.04761903 \\
\hline 9 & 6 & 6 & 3 & 0.23809522 & 0.23809522 \\
\hline 9 & 6 & 6 & 4 & 0.77380956 & 0.53571434 \\
\hline 9 & 6 & 6 & 5 & 0.98809524 & 0.21428568 \\
\hline 9 & 6 & 6 & 6 & 0.99999999 & 0.01190475 \\
\hline 9 & 7 & 1 & 0 & 0.22222221 & 0.22222221 \\
\hline 9 & 7 & 1 & 1 & 0.99999990 & 0.77777769 \\
\hline 9 & 7 & 2 & 0 & 0.02777776 & 0.02777776 \\
\hline
\end{tabular}


Sample Pages from the Hypergeometric Table (continued)

\begin{tabular}{|c|c|c|c|c|c|}
\hline $\mathrm{N}$ & $\mathrm{N*}$ & $\mathrm{K}^{*}$ & $\mathrm{x}$ & $\mathrm{PX}$ & $P X *$ \\
\hline 9 & 7 & 2 & 1 & 0.41666657 & 0.38888881 \\
\hline 9 & 7 & 2 & 2 & 0.99999981 & 0.58333325 \\
\hline 9 & 7 & 3 & 1 & 0.08333332 & 0.08333332 \\
\hline 9 & 7 & 3 & 2 & 0.58333327 & 0.49999995 \\
\hline 9 & 7 & 3 & 3 & 0.99999993 & 0.41666666 \\
\hline 9 & 7 & 4 & 2 & 0.16666663 & 0.16666663 \\
\hline 9 & 7 & 4 & 3 & 0.72222210 & 0.55555546 \\
\hline 9 & 7 & 4 & 4 & 0.99999984 & 0.27777774 \\
\hline 9 & 7 & 5 & 3 & 0.27777774 & 0.27777774 \\
\hline 9 & 7 & 5 & 4 & 0.83333320 & 0.55555546 \\
\hline 9 & 7 & 5 & 5 & 0.99999984 & 0.16666663 \\
\hline 9 & 7 & 6 & 4 & 0.41666666 & 0.41666666 \\
\hline 9 & 7 & 6 & 5 & 0.91666660 & 0.49999995 \\
\hline 9 & 7 & 6 & 6 & 0.99999993 & 0.08333332 \\
\hline 9 & 7 & 7 & 5 & 0.58333325 & 0.58333325 \\
\hline 9 & 7 & 7 & 6 & 0.97222205 & 0.38888881 \\
\hline 9 & 7 & 7 & 7 & 0.99999981 & 0.02777776 \\
\hline 9 & 8 & 1 & 0 & 0.11111110 & 0,11111110 \\
\hline 9 & 8 & 1 & 1 & 1.00000010 & 0.88888901 \\
\hline 9 & 8 & 2 & 1 & 0.22222221 & 0.22222221 \\
\hline 9 & 8 & 2 & 2 & 0.99999997 & 0.77777776 \\
\hline 9 & 8 & 3 & 2 & 0.33333336 & 0.33333336 \\
\hline 9 & 8 & 3 & 3 & 1.00000003 & 0.66666667 \\
\hline 9 & 8 & 4 & 3 & 0.44444441 & 0.44444441 \\
\hline 9 & 8 & 4 & 4 & 1.00000000 & 0.55555560 \\
\hline 9 & 8 & 5 & 4 & 0.55555560 & 0.55555560 \\
\hline 9 & 8 & 5 & 5 & 1.00000000 & 0.44444441 \\
\hline 9 & 8 & 6 & 5 & 0.66666667 & 0.66666667 \\
\hline 9 & 8 & 6 & 6 & 1.00000003 & 0.33333336 \\
\hline 9 & 8 & 7 & 6 & 0.77777787 & 0.77777787 \\
\hline 9 & 8 & 7 & 7 & 1.00000007 & 0.22222221 \\
\hline 9 & 8 & 8 & 7 & 0.88888926 & 0.88888926 \\
\hline 9 & 8 & 8 & 8 & 1.00000039 & 0.11111113 \\
\hline$\overline{10}$ & $\overline{1}$ & 1 & 0 & 0.90000001 & 0.90000001 \\
\hline 10 & 1 & 1 & 1 & 0.99999999 & 0.09999998 \\
\hline 10 & 2 & 1 & 0 & 0.80000000 & 0.80000000 \\
\hline 10 & 2 & 1 & 1 & 1.00000000 & 0.20000000 \\
\hline 10 & 2 & 2 & 0 & 0.62222222 & 0.62222222 \\
\hline 10 & 2 & 2 & 1 & 0.97777776 & 0.35555553 \\
\hline 10 & 2 & 2 & 2 & 0.99999998 & 0.02222222 \\
\hline 10 & 3 & 1 & 0 & 0.70000001 & 0.70000001 \\
\hline 10 & 3 & 1 & 1 & 1.00000000 & 0.29999999 \\
\hline 10 & 3 & 2 & 0 & 0.46666663 & 0.46666663 \\
\hline 10 & 3 & 2 & 1 & 0.93333326 & 0.46666663 \\
\hline 10 & 3 & 2 & 2 & 0.99999993 & 0.06666666 \\
\hline 10 & 3 & 3 & 0 & 0.29166663 & 0.29166663 \\
\hline 10 & 3 & 3 & 1 & 0.81666663 & 0.52500000 \\
\hline 10 & 3 & 3 & 2 & 0.99166659 & 0.17499996 \\
\hline 10 & 3 & 3 & 3 & 0.99999991 & 0.00833333 \\
\hline
\end{tabular}


Sample Pages from the Hypergeometric Table (continued)

\begin{tabular}{|c|c|c|c|c|c|}
\hline $\mathbf{N}$ & $N^{*}$ & $\mathrm{~K}^{*}$ & $\mathrm{X}$ & $\mathrm{PX}$ & PX* \\
\hline 10 & 4 & 1 & 0 & 0.59999999 & 0.59999999 \\
\hline 10 & 4 & 1 & 1 & 0.99999996 & 0.39999997 \\
\hline 10 & 4 & 2 & 0 & 0.33333332 & 0.33333332 \\
\hline 10 & 4 & 2 & 1 & 0.86666662 & 0.53333330 \\
\hline 10 & 4 & 2 & 2 & 0.99999994 & 0.13333332 \\
\hline 10 & 4 & 3 & 0 & 0.16666663 & 0.16666663 \\
\hline 10 & 4 & 3 & 1 & 0.66666663 & 0.50000000 \\
\hline 10 & 4 & 3 & 2 & 0.96666662 & 0.29999999 \\
\hline 10 & 4 & 3 & 3 & 0.99999995 & 0.03333332 \\
\hline 10 & 4 & 4 & 0 & 0.07142855 & 0.07142855 \\
\hline 10 & 4 & 4 & 1 & 0.45238087 & 0.38095232 \\
\hline 10 & 4 & 4 & 2 & 0.88095234 & 0.42857146 \\
\hline 10 & 4 & 4 & 3 & 0.99523802 & 0.11428569 \\
\hline 10 & 4 & 4 & 4 & 0.99999992 & 0.00476190 \\
\hline 10 & 5 & 1 & 0 & 0.50000004 & 0.50000004 \\
\hline 10 & 5 & 1 & 1 & 1.00000009 & 0.50000004 \\
\hline 10 & 5 & 2 & 0 & 0.22222221 & 0.22222221 \\
\hline 10 & 5 & 2 & 1 & 0.77777775 & 0.55555554 \\
\hline 10 & 5 & 2 & 2 & 0.99999996 & 0.22222221 \\
\hline 10 & 5 & 3 & 0 & 0.08333332 & 0.08333332 \\
\hline 10 & 5 & 3 & 1 & 0.50000001 & 0.41666669 \\
\hline 10 & 5 & 3 & 2 & 0.91666671 & 0.41666669 \\
\hline 10 & 5 & 3 & 3 & 1.00000003 & 0.08333332 \\
\hline 10 & 5 & 4 & 0 & 0.02380951 & 0.02380951 \\
\hline 10 & 5 & 4 & 1 & 0.26190476 & 0.23809525 \\
\hline 10 & 5 & 4 & 2 & 0.73809525 & 0.47619049 \\
\hline 10 & 5 & 4 & 3 & 0.97619050 & 0.23809525 \\
\hline 10 & 5 & 4 & 4 & 1.00000001 & 0.0238095 \\
\hline 10 & 5 & 5 & 0 & 0.00396825 & 0.00396825 \\
\hline 10 & 5 & 5 & 1 & 0.10317459 & 0.09920634 \\
\hline 10 & 5 & 5 & 2 & 0.49999995 & 0.39682535 \\
\hline 10 & 5 & 5 & 3 & 0.89682530 & 0.39682535 \\
\hline 10 & 5 & 5 & 4 & 0.99603164 & 0.09920634 \\
\hline 10 & 5 & 5 & 5 & 0.99999989 & 0.00396825 \\
\hline 10 & 6 & 1 & 0 & 0.39999995 & 0.39999995 \\
\hline 10 & 6 & 1 & 1 & 0.99999995 & 0.59999999 \\
\hline 10 & 6 & 2 & 0 & 0.13333332 & 0.13333332 \\
\hline 10 & 6 & 2 & 1 & 0.66666657 & 0.53333326 \\
\hline 10 & 6 & 2 & 2 & 0.99999990 & 0.33333332 \\
\hline 10 & 6 & 3 & 0 & 0.03333332 & 0.03333332 \\
\hline 10 & 6 & 3 & 1 & 0.33333326 & 0.29999994 \\
\hline 10 & 6 & 3 & 2 & 0.83333326 & 0.50000000 \\
\hline 10 & 6 & 3 & 3 & 0.99999990 & 0.16666663 \\
\hline 10 & 6 & 4 & 0 & 0.00476190 & 0.00476190 \\
\hline 10 & 6 & 4 & 1 & 0.11904758 & 0.11428569 \\
\hline 10 & 6 & 4 & 2 & 0.54761898 & 0.42857140 \\
\hline 10 & 6 & 4 & 3 & 0.92857122 & 0.38095225 \\
\hline 10 & 6 & 4 & 4 & 0.99999978 & 0.07142855 \\
\hline 10 & 6 & 5 & 1 & 0.02380951 & 0.02380951 \\
\hline
\end{tabular}


Sample Pages from the Hypergeometric Table (continued)

\begin{tabular}{|c|c|c|c|c|c|}
\hline $\mathrm{N}$ & $N *$ & $\mathrm{~K}^{*}$ & $\mathrm{X}$ & PX & PX* \\
\hline 10 & 6 & 5 & 2 & 0.26190474 & 0.23809522 \\
\hline 10 & 6 & 5 & 3 & 0.73809515 & 0.47619040 \\
\hline 10 & 6 & 5 & 4 & 0.97619037 & 0.23809522 \\
\hline 10 & 6 & 5 & 5 & 0.99999989 & 0.02380951 \\
\hline 10 & 6 & 6 & 2 & 0.07142855 & 0.07142855 \\
\hline 10 & 6 & 6 & 3 & 0.45238080 & 0.38095225 \\
\hline 10 & 6 & 6 & 4 & 0.88095219 & 0.42857140 \\
\hline 10 & 6 & 6 & 5 & 0.99523788 & 0.11428569 \\
\hline 10 & 6 & 6 & 6 & 0.99999978 & 0.00476190 \\
\hline 10 & 7 & 1 & 0 & 0.29999999 & 0.29999999 \\
\hline 10 & 7 & 1 & 1 & 0.99999995 & 0.69999996 \\
\hline 10 & 7 & 2 & 0 & 0.06666666 & 0.06666666 \\
\hline 10 & 7 & 2 & 1 & 0.53333329 & 0.46666663 \\
\hline 10 & 7 & 2 & 2 & 0.99999993 & 0.46666663 \\
\hline 10 & 7 & 3 & 0 & 0.00833333 & 0.00833333 \\
\hline 10 & 7 & 3 & 1 & 0.18333329 & 0.17499996 \\
\hline 10 & 7 & 3 & 2 & 0.70833329 & 0.52500000 \\
\hline 10 & 7 & 3 & 3 & 0.99999992 & 0.29166663 \\
\hline 10 & 7 & 4 & 1 & 0.03333332 & 0.03333332 \\
\hline 10 & 7 & 4 & 2 & 0.33333326 & 0.29999994 \\
\hline 10 & 7 & 4 & 3 & 0.83333321 & 0.49999995 \\
\hline 10 & 7 & 4 & 4 & 0.99999984 & 0.16666663 \\
\hline 10 & 7 & 5 & 2 & 0.08333332 & 0.08333332 \\
\hline 10 & 7 & 5 & 3 & 0.49999998 & 0.41666666 \\
\hline 10 & 7 & 5 & 4 & 0.91666663 & 0.41666666 \\
\hline 10 & 7 & 5 & 5 & 0.99999996 & 0.08333332 \\
\hline 10 & 7 & 6 & 3 & 0.16666663 & 0.16666663 \\
\hline 10 & 7 & 6 & 4 & 0.66666658 & 0.49999995 \\
\hline 10 & 7 & 6 & 5 & 0.96666653 & 0.29999994 \\
\hline 10 & 7 & 6 & 6 & 0.99999984 & 0.03333332 \\
\hline 10 & 7 & 7 & 4 & 0.29166663 & 0.29166663 \\
\hline 10 & 7 & 7 & 5 & 0.81666663 & 0.52500000 \\
\hline 10 & 7 & 7 & 6 & 0.99166659 & 0.17499996 \\
\hline 10 & 7 & 7 & 7 & 0.999999991 & 0.00833333 \\
\hline 10 & 8 & 1 & 0 & 0.19999997 & 0.19999997 \\
\hline 10 & 8 & 1 & 1 & 1.00000003 & 0.80000007 \\
\hline 10 & 8 & 2 & 0 & 0.02222222 & 0.02222222 \\
\hline 10 & 8 & 2 & 1 & 0.37777776 & 0.35555553 \\
\hline 10 & 8 & 2 & 2 & 1.00000001 & 0.62222227 \\
\hline 10 & 8 & 3 & 1 & 0.66666666 & 0.06666666 \\
\hline 10 & 8 & 3 & 2 & 0.53333329 & 0.46666663 \\
\hline 10 & 8 & 3 & 3 & 0.99999993 & 0.46666663 \\
\hline 10 & 8 & 4 & 2 & 0.13333332 & 0.13333332 \\
\hline 10 & 8 & 4 & 3 & 0.66666657 & 0.53333326 \\
\hline 10 & 8 & 4 & 4 & 0.99999993 & 0.33333336 \\
\hline 10 & 8 & 5 & 3 & 0.22222221 & 0.22222221 \\
\hline 10 & 8 & 5 & 4 & 0.77777781 & 0.55555560 \\
\hline 10 & 8 & 5 & 5 & 1.00000001 & 0.22222221 \\
\hline 10 & 8 & 6 & 4 & 0.33333336 & 0.33333336 \\
\hline
\end{tabular}


Sample Pages from the Hypergeometric Table (continued)

\begin{tabular}{|c|c|c|c|c|c|}
\hline $\mathrm{N}$ & $N^{*}$ & $\mathrm{~K} *$ & $\mathrm{X}$ & $\mathrm{PX}$ & $P^{*} *$ \\
\hline 10 & 8 & 6 & 5 & 0.86666661 & 0.53333326 \\
\hline 10 & 8 & 6 & 6 & 0.99999996 & 0.13333334 \\
\hline 10 & 8 & 7 & 5 & 0.46666673 & 0.46666673 \\
\hline 10 & 8 & 7 & 6 & 0.93333346 & 0.46666673 \\
\hline 10 & 8 & 7 & 7 & 1.00000013 & 0.06666668 \\
\hline 10 & 8 & 8 & 6 & 0.62222243 & 0.62222243 \\
\hline 10 & 8 & 8 & 7 & 0.97777797 & 0.35555553 \\
\hline 10 & 8 & 8 & 8 & 1.00000018 & 0.02222222 \\
\hline 10 & 9 & 1 & 0 & 0.09999998 & 0.09999998 \\
\hline 10 & 9 & 1 & 1 & 0.99999995 & 0.89999997 \\
\hline 10 & 9 & 2 & 1 & 0.19999997 & 0.19999997 \\
\hline 10 & 9 & 2 & 2 & 1.00000003 & 0.80000007 \\
\hline 10 & 9 & 3 & 2 & 0.29999999 & 0.29999999 \\
\hline 10 & 9 & 3 & 3 & 0.99999995 & 0.69999996 \\
\hline 10 & 9 & 4 & 3 & 0.39999992 & 0.39999992 \\
\hline 10 & 9 & 4 & 4 & 0.99999992 & 0.59999999 \\
\hline 10 & 9 & 5 & 4 & 0.50000004 & 0.50000004 \\
\hline 10 & 9 & 5 & 5 & 1.00000009 & 0.50000004 \\
\hline 10 & 9 & 6 & 5 & 0.59999999 & 0.59999999 \\
\hline 10 & 9 & 6 & 6 & 0.99999992 & 0.39999992 \\
\hline 10 & 9 & 7 & 6 & 0.69999996 & 0.69999996 \\
\hline 10 & 9 & 7 & 7 & 0.99999999 & 0.30000003 \\
\hline 10 & 9 & 8 & 7 & 0.80000018 & 0.80000018 \\
\hline 10 & 9 & 8 & 8 & 1.00000010 & 0.19999994 \\
\hline 10 & 9 & 9 & 8 & 0.89999984 & 0.89999984 \\
\hline 10 & 9 & 9 & 9 & 0.99999982 & 0.09999998 \\
\hline 11 & 1 & 1 & 0 & 0.90909091 & 0.90909091 \\
\hline 11 & 1 & 1 & 1 & 0.99999998 & 0.09090507 \\
\hline 11 & 2 & 1 & 0 & 0.81818181 & 0.81818181 \\
\hline 11 & 2 & 1 & 1 & 0.99999998 & 0.18181816 \\
\hline 11 & 2 & 2 & 0 & 0.65454542 & 0.65454542 \\
\hline 11 & 2 & 2 & 1 & 0.98181814 & 0.32727272 \\
\hline 11 & 2 & 2 & 2 & 0.99999995 & 0.01818181 \\
\hline 11 & 3 & 1 & 0 & 0.72727271 & 0.72727271 \\
\hline 11 & 3 & 1 & 1 & 0.99999997 & 0.27272726 \\
\hline 11 & 3 & 2 & 0 & 0.50909089 & 0.50909089 \\
\hline 11 & 3 & 2 & 1 & 0.94545452 & 0.43636362 \\
\hline 11 & 3 & 2 & 2 & 0.99999996 & 0.05454545 \\
\hline 11 & 3 & 3 & 0 & 0.33939391 & 0.33939391 \\
\hline 11 & 3 & 3 & 1 & 0.84848481 & 0.50909090 \\
\hline 11 & 3 & 3 & 2 & 0.99393935 & 0.14545455 \\
\hline 11 & 3 & 3 & 3 & 0.99999996 & 0.00606060 \\
\hline 11 & 4 & 1 & 0 & 0.63636363 & 0.63636363 \\
\hline 11 & 4 & 1 & 1 & 0.99999999 & 0.36363637 \\
\hline 11 & 4 & 2 & 0 & 0.38181816 & 0.38181816 \\
\hline 11 & 4 & 2 & 1 & 0.89090901 & 0.50909085 \\
\hline 11 & 4 & 2 & 2 & 0.99999991 & 0.10909090 \\
\hline 11 & 4 & 3 & 0 & 0.21212120 & 0.21212120 \\
\hline 11 & 4 & 3 & 1 & 0.72121204 & 0.50909085 \\
\hline
\end{tabular}




\section{LIST OF REFERENCES}

1. Wiesen, J. M., Owen, D. B., and Steck, G. P., A Discussion of the Analysis of $2 \times 2$ Tables, Sandia Corporation Technical Memorandum 170-56(51), October 24, 1956 .

2. Feller, W. , An Introduction to Probability Theory and Its Applications, John Wiley \& Sons, Inc., Vol. I, Second Edition, 1957.

3. Epstein, B., "Tables for the Distribution of the Number of Exceedances, " Annals of Mathematical Statistics, Vol. 25 (1954), pp. 762-768.

4. Gumbel, E. J., Statistics of Extremes, Columbia University Press, 1958, pp. 58-67.

5. Mann, H. B., and Whitney, D. R., "On a Test of Whether One of Two Random Variables is Stochastically Larger than the Other," Annals of Mathematical Statistics, Vol. 18 (1947), pp. 50-60.

6. Owen, D. B., Distribution-Free Tolerance Limits, Sandia Corporation Technical Memorandum 66A-57(51), June 24, 1957.

7. Owen, D. B., and Gilbert, E. J., The Relationship of the Binomial Probability Distribution to Other Probability Distributions with a Selected Bibliography on the Subject, Sandia Corporation Technical Memorandum SCTM 1-59(51), June 22, 1959. 